\title{
The sensitivity of the costs of reducing emissions from deforestation and degradation (REDD) to future socioeconomic drivers and its implications for mitigation policy design
}

\author{
Mykola Gusti $^{1,2}$ (D) Nicklas Forsell $^{1} \cdot$ Petr Havlik $^{1}$ • \\ Nikolay Khabarov ${ }^{1}$ - Florian Kraxner ${ }^{1}$. \\ Michael Obersteiner ${ }^{1}$
}

Received: 20 June 2017 / Accepted: 21 May 2018 /Published online: 8 June 2018

(C) The Author(s) 2018

\begin{abstract}
Climate change mitigation policies for the land use, land use change, and forestry (LULUCF) sector are commonly assessed based on marginal abatement cost curves (MACC) derived from optimization models or engineering approaches. Yet, little is known about the space of validity of MACCs and how they are influenced by changes in main underlying drivers. In this study, we apply the Global Forest Model (G4M) to explore the sensitivity of MACCs to variation of socioeconomic drivers of deforestation, afforestation, and forest management activities. Particularly, three key factors are considered: (I) wood price, as an indicator of timber market developments; (II) agricultural land price, as a proxy representing the developments on agricultural markets; and (III) corruption coefficient, representing the progress in institutional development and measuring abatement costs use efficiency. The results indicate that the MACCs are more sensitive to the corruption coefficient than to agricultural land price and wood price. Furthermore, we find that the MACCs are more robust with high carbon dioxide $\left(\mathrm{CO}_{2}\right)$ price and that the sensitivity of the MACCs is higher at low $\mathrm{CO}_{2}$ prices. In general, it can be concluded that when assessing medium-term mitigation policies characterized by low $\mathrm{CO}_{2}$ prices, MACCs need to be developed in-line with institutions currently in place. When designing long-term mitigation policy characterized by high $\mathrm{CO}_{2}$ prices, the role of the analyzed drivers in MACCs estimation is less important.
\end{abstract}

Electronic supplementary material The online version of this article (https://doi.org/10.1007/s11027-0189817-9) contains supplementary material, which is available to authorized users.

Mykola Gusti

gusti@iiasa.ac.at

1 International Institute for Applied Systems Analysis (IIASA), Schlossplatz 1, 2361 Laxenburg, Austria

2 Lviv Polytechnic National University, Lviv, Ukraine 
Keywords Marginal abatement cost curve $\cdot$ Sensitivity $\cdot$ Institutional quality $\cdot$ Economic parameters $\cdot$ Mitigation policy $\cdot$ MACC uncertainty

\section{Introduction}

To address forest-related climate mitigation measures globally reducing emissions from deforestation and degradation (REDD) mechanism has been introduced into the United Nations Framework Convention on Climate Change (UNFCCC). The introduction has been evolving from 2005 to 2015 at the Conferences of the Parties (COP) to the UNFCCC (UNREDD 2016). Currently, implementation of the REDD mechanism is seen as one of the important practices for reaching the $2^{\circ}$ climate change mitigation target cost effectively. In particular, REDD can be implemented relatively fast that allows more time for development of mitigation technologies in other sectors (Houghton et al. 2015; Fricko et al. 2017). Inclusion of REDD credits in the global carbon market may decrease the mitigation costs substantially (Anger and Sathaye 2008; den Elzen et al. 2009; Bosetti et al. 2011; Angelsen et al. 2014; Bosello et al. 2015).

The marginal abatement cost curve (MACC) relates the potential of greenhouse gas (GHG) emissions reduction over a baseline to the costs of such reduction. MACCs are often used by research institutions, consultancy companies, and governments for analysis of mitigation policies (e.g., Valatin 2012; Wagner et al. 2012; Radov et al. 2012; McKinsey and Company 2013; EPA 2013). MACCs are constructed, in particular using integrated assessment models and provide information for analysis of such policy instruments as implementation of a carbon dioxide $\left(\mathrm{CO}_{2}\right)$ tax or a cap-and-trade system (Kesicki 2011; Kesicki and Strachan 2011). In particular, MACCs are used for simulation of emission permits, taking into account the uncertainty of emissions (Pałka et al. 2018; Pickl 2018).

MACCs have been used for the analysis of REDD mitigation options in a number of studies, for example (den Elzen et al. 2009; Coren et al. 2011; Bosetti et al. 2011; Angelsen et al. 2014; Suyanto et al. 2014; Bosello et al. 2015). Kesicki and Strachan (2011) highlight the importance of taking into account uncertainties of MACCs if the MACCs are used for decision making. Experts employing MACCs for policy analysis need to be aware of the uncertainty in the MACCs' estimates, as this uncertainty can influence the outcome of the analysis. In the case of implementation of a $\mathrm{CO}_{2}$ tax, an uncertain MACC may have a high influence on the expected reduction of $\mathrm{CO}_{2}$ emissions (Fig. 1a). In the case of the introduction of a cap-andtrade system, an uncertain MACC may have a high impact on the $\mathrm{CO}_{2}$ price that can be expected from a specific volume of carbon allowances (Fig. 1b). Considering the uncertainty of MACCs, authors commonly mention the importance of baseline and modeling assumptions or ignorance of some factors when MACCs are constructed or applied (EPA 2013; Michaelova and Jotzo 2003; Vogt-Schilb et al. 2015; Ekins et al. 2011; Schneider and McCarl 2006).

Klepper and Peterson (2003) studied sensitivity of MACCs in the energy sector of world regions to energy prices using the Dynamic Applied Regional Trade (DART) computable general equilibrium model. Kesicki (2013) investigated the sensitivity of MACCs to changes in fossil fuel prices in the United Kingdom (UK) transport sector using the UK MARKAL (acronym for MARKet Allocation) energy system model. The study found that the MACCs are more robust at higher $\mathrm{CO}_{2}$ tax levels than at lower tax levels. Eory et al. (2014) performed MACC uncertainty assessment for soil emissions of Scotland; they found that uncertainty in the economically optimal greenhouse gas (GHG) abatement rate (where MACC intercepts the marginal damage 

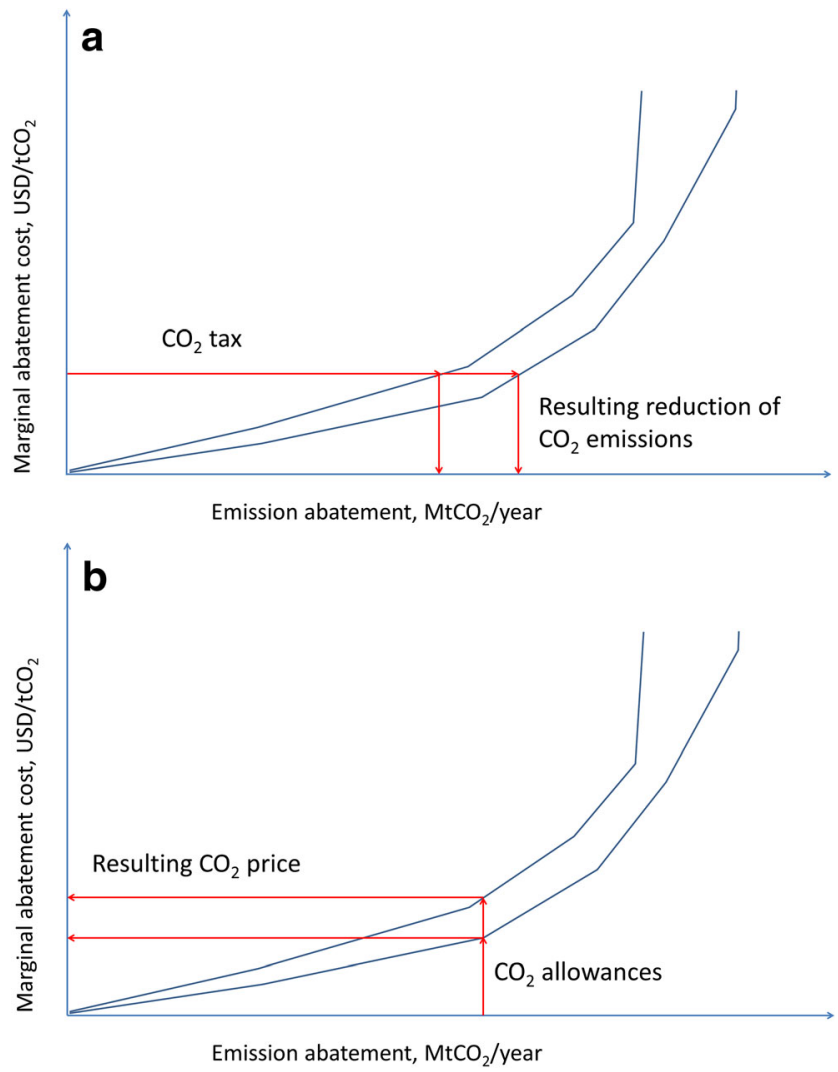

Fig. 1 Illustration of influence of the marginal abatement cost curve uncertainty on resulting reduction of $\mathrm{CO}_{2}$ emissions in case of $\mathrm{CO}_{2}$ tax implementation (a) and on $\mathrm{CO}_{2}$ price in case of a cap-and-trade system (b)

cost curve) was high; however, the ranking of the cost-effective measures was found to be relatively robust. Eory et al. (2018) studied uncertainty of MACC on the crop and soil management mitigation options for northern UK agriculture applying Monte Carlo method; in their study, the adoption rate of mitigation options and abatement rate are the main uncertainty determinants. Webster et al. (2010) studied the influence of uncertainties in gross domestic product (GDP) growth rate, the rate of autonomous energy efficiency improvement, and the elasticities of substitution in the production functions on mitigation policy mechanism using a static computable general equilibrium model of the United States (US) economy. Schneider and McCarl (2006) studied how alternative assumptions of economic market adjustments allowed the scope of mitigation alternatives and the region of focus influence the mitigation potential and costs in agriculture and forestry sectors in the US using the Agricultural Sector and Mitigation of Greenhouse Gas Model (ASMGHG); they concluded that the different assumptions result in a range of economic mitigation potentials from -55 to $+85 \%$ compared to the baseline mitigation scenario; the spread of the mitigation potential is larger at higher $\mathrm{CO}_{2}$ prices because the mitigation shifts from agriculture to forestry sector (afforestation and energy crops plantations) that competes with agriculture for land. Van Vuuren et al. (2009) compared GHG mitigation potentials and costs (all GHG gasses and economy sectors) for 2030 obtained from six 
integrated assessment models (IAM) employing statistical analysis and combining the results of different model studies and two bottom-up assessments; they found that the spread of the mitigation potential estimated by the IAMs is larger at lower $\mathrm{CO}_{2}$ prices than at higher $\mathrm{CO}_{2}$ prices and overall variation of the results is greater at lower $\mathrm{CO}_{2}$ prices. Fan et al. (2017) studied MACC under integrated uncertainty (technology-investment cost, energy-saving potential, and energy price) in China's passenger car sector; they found that the uncertainties significantly influence the $\mathrm{CO}_{2}$ abatement cost of emission reduction technologies for the passenger cars; however, the uncertainties do not change the order of considered technologies.

To estimate uncertainty of the REDD MACCs, researchers usually compare the results of different models (e.g., Kindermann et al. 2008; den Elzen et al. 2009; Coren et al. 2011). Overmars et al. (2014) studied the opportunity costs of reducing deforestation $\mathrm{CO}_{2}$ emissions using a global economic model LEITAP (acronym for Landbouw Economisch Instituut Trade Analysis Project) interlinked with the Integrated Model to Assess the Global Environment (IMAGE); the authors performed a sensitivity analysis of the cost per tonne $\mathrm{CO}_{2}$ to the variation of land supply elasticity and land-labor/capital substitution elasticity. According to their results, relative change of the cost per ton $\mathrm{CO}_{2}$ is the largest (167\%) in Sub-Saharan Africa-the region with the lowest opportunity costs of about $0.6 \mathrm{USD} / \mathrm{tCO}_{2}$, middle (35\%) in Central and South America - the region with the opportunity costs of about $5 \mathrm{USD} / \mathrm{tCO}_{2}$, and the least (14\%) in South East Asia - the region with the opportunity costs of about $50 \mathrm{USD} / \mathrm{tCO}_{2}$. Overmars et al. (2014) did not consider the whole MACC, but only the minimum opportunity costs. However, the uncertainties in REDD-related MACCs in relation to quality of input parameters have not been assessed in the literature available in the field. One could expect a little effect of model parameters deviation on MACC if the deviation is the same at zero and non-zero model runs (in such case, the parameter deviation is a kind of bias eliminated when calculating MACC). However, if the model is non-linear, the shift of parameters can influence MACC.

This study is aimed at answering the following questions: what is the sensitivity of the REDD-related MACCs to key socio-economic drivers and how uncertainties can impact GHG abatement policies related to the forest sector?

In the study, we choose prices of wood and agriculture land as the important and uncertain economic drivers of land use change, and quality of institutions as important factor for controlling land use change. The wood and agriculture land prices represent two economic alternatives of competitive land use, i.e., forestry for wood production or agriculture for food, industrial crops, and energy crops production. According to the analysis of IAM quantification of the SSPs by Fricko et al. (Fricko et al. 2017), the different scenarios may result in changes of the agriculture commodity prices from -60 to $+50 \%$ by 2100 comparing to 2005 . GHG mitigation activities, in addition, may result in an increase of the agriculture commodity prices by $110-570 \%$. In its turn, corruption (as an indicator of low quality of institutions) is one of the major threats to the effectiveness of the REDD programs and it is present in the countries where REDD programs are implemented (Sheng et al. 2016). For example, the corruption coefficient used in the Global Forest Model (G4M) is estimated by Kindermann et al. (2006) as an average of the percentile rank from "political stability," "government effectiveness," and "control of corruption" from (Kaufmann et al. 2005). The relative uncertainty of the 
estimates of the corruption coefficient components ranges from a few percent to much over $100 \%$ for some countries where it is difficult to get reliable information (e.g., North Korea, Afghanistan).

We apply G4M to study the sensitivity of MACCs to institutional quality represented with a corruption coefficient and prices of wood and agriculture land. We also compare the G4M-derived MACCs to the MACCs obtained using other models to understand how much uncertainty in MACCs are due to differences in model assumptions versus input data uncertainties. In the final section of this article, the possible influence of features of the MACC uncertainties on the REDD mitigation policy design are considered.

G4M simulates afforestation, deforestation, and forest management directed at sustainable wood production, response of the aforementioned processes to $\mathrm{CO}_{2}$ price incentives and respective $\mathrm{CO}_{2}$ emissions. It is widely used for estimation of REDD mitigation potential (for example, contribution to the Eliasch Review (Eliasch 2008), quantification of the IPCC RCP 8.5 scenario (Riahi et al. 2011), the World Bank assessment (Havlík et al. 2015), quantification of the shared socio-economic pathways (SSP) (Fricko et al. 2017), and development of the European Union ( EU) projections (Böttcher et al. 2012; Capros et al. 2013, 2016; Frank et al. 2016; Forsell et al. 2016)).

\section{Method}

\subsection{G4M model}

The G4M is a geographically explicit computer model to assess land use change and forest management decision making. The decisions are calculated for $0.5 \times 0.5^{\circ}$ grid cells, which approximately correspond to a $50 \times 50 \mathrm{~km}$ grid taking sub-grid information into account as described in (Kindermann et al. 2006, 2008; Gusti et al. 2008; Gusti and Kindermann 2011; see also the model website: http://www.iiasa.ac.at/web/home/research/modelsData/G4M.en. html).

Land use change decisions are modeled on the basis of comparing net present value of forestry vis-à-vis the net present value of land use from agriculture. Deforestation is modeled to take place in a grid, if the net present value of agriculture together with benefits from selling wood after the clear-cut of the forest is greater than net present value of forestry (sustainable production of wood during multiple rotation periods) multiplied by a hurdle coefficient. The net present value of agriculture is modeled with an agricultural land price in a form of CobbDouglas production function, in which agricultural suitability and population density are independent variables (Benitez and Obersteiner 2006). In the model deforestation, afforestation and wood production are prohibited in conservation and nature protection areas. Afforestation takes place in a grid, in which there is land that can be afforested (i.e., not under buildings and roads or secured for agriculture), the environmental conditions are suitable for forestry, and the net present value of forestry multiplied by a hurdle coefficient is greater than the net present value of agriculture. Economic policies, e.g., carbon tax in case of deforestation or payments for carbon accumulated additionally in forest ecosystem in case of a/reforestation, add value to the maintenance of keeping the forest carbon stock. The hurdle coefficient as well as country-specific adjustment factors for deforestation and afforestation rates are derived from applying a calibration method to match historic predictions to FAO and IPCC values (Gusti 
et al. 2008). The deforestation rate (amount of forest land that can be converted to agricultural land during 1 year), and afforestation rate (amount of agricultural land on which forest can be planted during 1 year) are modeled to be also a function of gross domestic product per capita (GDP), population density, and agricultural suitability (Kindermann et al. 2006, 2008; Gusti and Kindermann 2011).

Forest management decisions are made to match simulated wood production for each country to endogenously determined wood demand (provided by GLOBIOM in current study). Forest management options are adjustment of rotation time, thinning intensity, and variation of forest area used for sustainable wood production (Gusti 2010).

Emissions from deforestation include emissions from forest biomass, dead organic matter (immediate loss of dead wood and decomposition of litter), and decomposition of up to $40 \%$ of soil organic matter. To assess carbon losses from deforestation, all carbon pools over time were tracked. Likewise, the evolution of carbon pools resulting from afforestation are tracked over time for all respective carbon pools. Emissions due to forest management are estimated as living biomass carbon stock change over time reflecting forest growth rate dependence on time and reaction on logging. Formal description of the model is presented in the online resource.

\subsection{Studying MACCs sensitivity to the variation of G4M input parameters}

The sensitivity of MACCs to the variation of three G4M parameters selected in the consultations among the project ${ }^{1}$ partners are studied: corruption coefficient $(c r)$, wood price $(w)$ $\left[\mathrm{USD} / \mathrm{m}^{3}\right]$, and agriculture land price $(l)[\mathrm{USD} / \mathrm{ha}]$. The corruption coefficient measures the efficiency of incurred costs for abatement: $c r=1$ (highest efficiency) means that no abatement costs are consumed by corruption and $c r=0$ (lowest efficiency) means that all costs are consumed by corruption.

The G4M model ran for a number of $\mathrm{CO}_{2}$ price scenarios: initial prices starting in $2020(0$, $1,3,5,10,15,20,25,30,40,50,60,80,100,120 \mathrm{USD} / \mathrm{tCO}_{2}$ ) and rising $5 \%$ per year (that results in $\mathrm{CO}_{2}$ price range of 4-520 USD/ton $\mathrm{CO}_{2}$ in 2050) using standard parameter values as in Kindermann et al. (2008) and Gusti and Kindermann (2011). For the purposes of sensitivity analysis, the values $c r, w$, and $l$ mentioned above are varied: decreased/increased by $1,2.5,5$, 10,50 , and $90 \%$ (only single parameter was changed during each run). For a year within the range 2020-2050, a MACC is defined as a difference of the biomass $\mathrm{CO}_{2}$ emissions at zero $\mathrm{CO}_{2}$ price and a non-zero $\mathrm{CO}_{2}$ price. The emissions include afforestation, deforestation, and forest management components. The parameter deviation was applied to all $\mathrm{CO}_{2}$ price runs, thus serving as a bias for MACC. For the run, G4M setup for quantification of SSP scenarios was used (Fricko et al. 2017), in particular G4M and GLOBIOM (Global Biosphere Management) (http://www.globiom.org/) models have been interlinked as in the IIASA Integrated Assessment Framework, population and GDP follow SSP2 scenario (Dellink et al. 2017), wood demand, regional agriculture land prices, and wood prices are estimated by GLOBIOM model under assumption of bioenergy demand of 50PJ/year, country-specific afforestation, and deforestation rates have been calibrated to match respective 2000-2010 average data obtained from FAO FRA 2010.

\footnotetext{
${ }^{1}$ The project "Options Market and Risk-Reduction Tools for REDD+" funded by the Norwegian Agency for Development Cooperation under agreement number QZA-0464 QZA-13/0074.
} 
The 12 MACC variations for each parameter were calculated. The results were assigned the following notations: $c r p V, c r m V, w p V, w m V, \operatorname{lp} V$, and $\operatorname{lm} V$, where $p$ means an increase of a parameter, $m$ means a decrease of a parameter, and $V$ means $1,2.5,5,10,50$, or $90 \%$ change of the parameter. Because of the limited space of the paper, detailed analysis of the MACC sensitivities to 10,50 , and $90 \%$ variation of the parameters globally and for three countries, Brazil, Indonesia, and Mexico, for the year 2030 are presented. Additional information is provided in the online resource.

\section{Results}

\subsection{Brazil}

At $1-5 \%$ variation of the parameters deviations of the MACC of total biomass, land use change and forestry emissions for Brazil follow the shape of respective deviations at $10 \%$ variation of the parameters with smaller amplitude.

At $10 \%$ variation of the parameters, the MACC is most sensitive when $\mathrm{CO}_{2}$ price is 5 $\mathrm{USD} / \mathrm{tCO}_{2}$ (Fig. $\mathrm{S} 1 \mathrm{a}-\mathrm{c}$ in the online resource). At this $\mathrm{CO}_{2}$ price, increase of the corruption coefficient (means less abatement costs are consumed by corruption) has the highest effect on the MACC-the efficiency of abatement costs increase by $57 \mathrm{MtCO}_{2} /$ year (Fig. S1c in the online resource). The sensitivity to the parameters diminishes very rapidly with the $\mathrm{CO}_{2}$ price increase. Decrease of the corruption coefficient by $10 \%$ causes deviation of $\mathrm{MACC}$ to $-45 \mathrm{MtCO}_{2}$ /year. Agriculture land price variation by $10 \%$ has the largest effect at 10-20 and over $80 \mathrm{USD} / \mathrm{tCO}_{2}$ (deviation of MACC up to 42 $\mathrm{MtCO}_{2}$ /year) (Fig. S1a in the online resource), while variation of wood price has the largest effect for the $\mathrm{CO}_{2}$ price range 25-60 $\mathrm{USD} / \mathrm{tCO}_{2}$ (deviation of MACC up to 16 $\mathrm{MtCO}_{2} /$ year) (Fig. S1b and Table $\mathrm{S} 1$ in the online resource).

At $50 \%$ variation of the parameters, the MACC is most sensitive when $\mathrm{CO}_{2}$ price is 10 $\mathrm{USD} / \mathrm{tCO}_{2}$ (Fig. Sla-c in the online resource). At this $\mathrm{CO}_{2}$ price, decrease of the corruption coefficient causes deviation of the MACC by $-444 \mathrm{MtCO}_{2} /$ year (Fig. S1c in the online resource). The effect of the corruption coefficient variation diminishes rapidly and after 25 $\mathrm{USD} / \mathrm{tCO}_{2}$ is close to zero. At $\mathrm{CO}_{2}$ prices over $25 \mathrm{USD} / \mathrm{tCO}_{2}$, wood (Fig. S1b in the online resource) and agricultural land (Fig. S1a in the online resource) prices have a non-zero effect (deviation of $\mathrm{MACC}$ up to $7 \mathrm{MtCO}_{2} /$ year). The corruption coefficient has the largest effect on MACC across the three parameters at 3 and 10-25 USD/tCO ${ }_{2}$, wood price - at 1 and 40-120 $\mathrm{USD} / \mathrm{tCO}_{2}$, and agriculture land price - at 5 and $10 \mathrm{MtCO}_{2} /$ year. Wood price variation causes maximum deviation of $\mathrm{MACC}\left(63 \mathrm{MtCO}_{2} /\right.$ year $)$ at $5 \mathrm{USD} / \mathrm{tCO}_{2}$. Agriculture land price causes deviation of MACC (407 $\mathrm{MtCO}_{2} /$ year) at $5 \mathrm{USD} / \mathrm{tCO}_{2}$. For more information, see Table $\mathrm{S} 2$ in the online resource.

At $90 \%$ variation of the parameters, the MACC is most sensitive at $15 \mathrm{USD} / \mathrm{tCO}_{2}$ (Fig. $\mathrm{S} 1 \mathrm{a}-\mathrm{c}$ in the online resource). At this $\mathrm{CO}_{2}$ price, decrease of the corruption coefficient causes deviation of the MACC by $-644 \mathrm{MtCO}_{2} /$ year (Fig. S1c in the online resource). The effect of the corruption coefficient variation diminishes slowly and has the highest impact on MACC at $1,10-100 \mathrm{USD} / \mathrm{tCO}_{2}$. Agriculture land price has a bit lower impact with maximum at $\mathrm{CO}_{2}$ price $3 \mathrm{USD} / \mathrm{tCO}_{2}$ (Fig. $\mathrm{S} 1 \mathrm{a}$ in the online resource); it prevails the corruption coefficient effect at 3,5, and $120 \mathrm{USD} / \mathrm{tCO}_{2}$. Wood price reaches its maximum effect on $\mathrm{MACC}\left(128 \mathrm{MtCO}_{2} /\right.$ year) at $\mathrm{CO}_{2}$ price $5 \mathrm{USD} / \mathrm{tCO}_{2}$ (Fig. $\mathrm{S} 1 \mathrm{~b}$ in the online resource), while the 
agriculture land price - at $\mathrm{CO}_{2}$ price $3 \mathrm{USD} / \mathrm{tCO}_{2}\left(562 \mathrm{MtCO}_{2} /\right.$ year). For more information, see Table S3 in the online resource.

The corruption coefficient has the largest impact on the MACC at all levels of the parameter changes. Increasing the amplitude of the parameter variation causes the maximum impact shifts from $5 \mathrm{USD} / \mathrm{tCO}_{2}$ to $15 \mathrm{USD} / \mathrm{tCO}_{2}$. Agriculture land and wood prices have a noticeable effect at very low and $\mathrm{CO}_{2}$ prices greater than $30 \mathrm{USD} / \mathrm{tCO}_{2}$. In the case of $10 \%$ variation, all the three parameters have the strongest impact at $5 \mathrm{USD} / \mathrm{tCO}_{2}$. Increase of the parameter variation amplitude defuses the $\mathrm{CO}_{2}$ price at which individual parameters cause maximum deviation of MACC (Tables S1-S3 in the online resource).

In the case of Brazil, the sensitivity of MACC related to emissions from deforestation determines the shape and magnitude of the sensitivity of the total biomass emission MACC. For the $10 \%$ parameters variations, the sensitivity of the forest management MACC is considerably smaller than the MACC related to emissions from deforestation for variations of the corruption rate coefficient ( $57 \mathrm{vs} .7 \mathrm{MtCO}_{2}$ /year) and agriculture land price (40 vs. 1.8-2 $\mathrm{MtCO}_{2} /$ year), but it is comparable for the wood price variation (13 vs. $8 \mathrm{MtCO}_{2} /$ year). However, the maximum of the forest management MACC sensitivity is shifted to 3 USD/ $\mathrm{tCO}_{2}$ for the wood price and corruption coefficient and to $10 \mathrm{USD} / \mathrm{tCO}_{2}$ for agriculture land price variations. Sensitivity of the afforestation emission MACC to the studied parameters is of one-two orders of magnitude smaller than the other two components of the total emission MACC and has a different shape; it increases linearly with $\mathrm{CO}_{2}$ price increase for the agricultural land price and wood price, but has a maximum at $40 \mathrm{USD} / \mathrm{tCO}_{2}$ for the corruption coefficient. From the point of view of MACC non-linearity by the parameters, the forest management MACC has the most complex shape.

\subsection{Indonesia}

At $1-10 \%$ variation of the parameters, the MACC is most sensitive when $\mathrm{CO}_{2}$ price is $5 \mathrm{USD} /$ $\mathrm{tCO}_{2}$ (Fig. S2a-c in the online resource). In the case of $10 \%$ variation of the parameters at this $\mathrm{CO}_{2}$ price, increase of agriculture land price has the highest effect on the MACC - the efficiency of abatement costs increases by $28 \mathrm{MtCO}_{2} /$ year (Fig. S2a in the online resource). Decrease of the corruption coefficient causes a bit less deviation of the MACC giving additional abatement of $27 \mathrm{MtCO}_{2} /$ year (Fig. S2c in the online resource). The sensitivity to the parameters diminishes very rapidly with the $\mathrm{CO}_{2}$ price increase. Unlike Brazil, deviation of the MACC has a spike at a $\mathrm{CO}_{2}$ price of $120 \mathrm{USD} / \mathrm{tCO}_{2}$ with the highest negative sensitivity to the corruption coefficient yielding $9 \mathrm{MtCO}_{2}$ year less abatement if the corruption coefficient is decreased by $10 \%$. The increase of wood and agriculture land prices causes shifting of the MACC by -7 and $8 \mathrm{MtCO}_{2}$ /year, respectively, at $120 \mathrm{USD} / \mathrm{tCO}_{2}$ (Fig. S2b in the online resource). Across the parameters, the corruption coefficient has the highest impact on the MACC at 10, 40-60, and $120 \mathrm{USD} / \mathrm{tCO}_{2}$, agriculture land price - at $1-5,15-25$, and $80 \mathrm{USD} /$ $\mathrm{tCO}_{2}$. Wood price deviation has the maximum effect only at 30 and $100 \mathrm{MtCO}_{2} /$ year (see Table S4 in the online resource).

At $50 \%$ variation of the parameters, the MACC is most sensitive when the $\mathrm{CO}_{2}$ price is 3 $\mathrm{USD} / \mathrm{tCO}_{2}$ (Fig. S3a-c in the online resource). At this $\mathrm{CO}_{2}$ price, a decrease of agriculture land price causes deviation of the MACC by $177 \mathrm{MtCO}_{2}$ /year (Fig. S3a in the online resource). Agriculture land price increase has maximum effect on MACC across the three parameters at the $\mathrm{CO}_{2}$ prices from 1 to $5 \mathrm{USD} / \mathrm{tCO}_{2}$ then it decreases rapidly to $3-9 \mathrm{MtCO}_{2}$ /year (see Table S5 in the online resource). Decrease of the corruption coefficient causes deviation of the 
MACC from $138 \mathrm{MtCO}_{2} /$ year at $5 \mathrm{USD} / \mathrm{tCO}_{2}$ to $-23 \mathrm{MtCO}_{2} /$ year at $120 \mathrm{USD} / \mathrm{tCO}_{2}$ (Fig. S2c in the online resource); it has the strongest impact on MACC across the parameters at 10-30 and $80-120 \mathrm{USD} / \mathrm{tCO}_{2}$. Wood price increase has the largest effect across the parameters (13$22 \mathrm{MtCO}_{2}$ /year) at $\mathrm{CO}_{2}$ prices from 40 to $60 \mathrm{USD} / \mathrm{tCO}_{2}$. Wood price variation reaches its maximum effect on the MACC $\left(22 \mathrm{MtCO}_{2} /\right.$ year) at $\mathrm{CO}_{2}$ price $50 \mathrm{USD} / \mathrm{tCO}_{2}$ (Fig. S2b in the online resource).

At $90 \%$ variation of the parameters, the MACC is most sensitive when $\mathrm{CO}_{2}$ price is $1 \mathrm{USD} /$ $\mathrm{tCO}_{2}$ (Fig. S2a-c in the online resource). At this $\mathrm{CO}_{2}$ price, a decrease of agriculture land price causes deviation of the MACC by $305 \mathrm{MtCO}_{2}$ /year (Fig. S2a) in the online resource. The agriculture land price increase has a maximum effect on the MACC across the three parameters at $\mathrm{CO}_{2}$ prices from 1 to $5 \mathrm{USD} / \mathrm{tCO}_{2}$, then it decreases rapidly to $32-51 \mathrm{MtCO}_{2} /$ year (see Table S6 in the online resource). A decrease of the corruption coefficient causes rapid increase of deviation of the MACC from $-3 \mathrm{MtCO}_{2} /$ year at $1 \mathrm{USD} / \mathrm{tCO}_{2}$ to $-287 \mathrm{MtCO}_{2} /$ year at 25 $\mathrm{USD} / \mathrm{tCO}_{2}$, then slow decrease of the magnitude to $-60 \mathrm{MtCO}_{2} /$ year at $120 \mathrm{USD} / \mathrm{tCO}_{2}$ (Fig. $\mathrm{S} 2 \mathrm{c}$ in the online resource); it has the strongest impact on MACC across the parameters at 10 $120 \mathrm{USD} / \mathrm{tCO}_{2}$. A wood price makes a maximum impact on the MACC (29 $\mathrm{MtCO}_{2} /$ year) at $\mathrm{CO}_{2}$ price $3 \mathrm{USD} / \mathrm{tCO}_{2}$ (Fig. S2b in the online resource).

An agriculture land price decrease has the largest impact on MACC at all levels of the parameter changes. Increasing the amplitude of the parameter variation, the maximum impact shifts from $5 \mathrm{USD} / \mathrm{tCO}_{2}$ to $1 \mathrm{USD} / \mathrm{tCO}_{2}$. The corruption coefficient has the largest impact on MACC at $\mathrm{CO}_{2}$ prices greater than $5 \mathrm{USD} / \mathrm{tCO}_{2}$ for 50 and $90 \%$ variation of the parameters (see Tables S4-S6 in the online resource).

\subsection{Mexico}

At $1-10 \%$ variation of the parameters, the MACC is most sensitive when the $\mathrm{CO}_{2}$ price is 10 $\mathrm{USD} / \mathrm{tCO}_{2}$ (Fig. S3a-c in the online resource). In the case of $10 \%$ variation of the parameters at this $\mathrm{CO}_{2}$ price, a decrease of the corruption coefficient causes deviation of the MACC by -9 $\mathrm{MtCO}_{2} /$ year, while an increase of the corruption coefficient gives an additional abatement of 8 $\mathrm{MtCO}_{2} /$ year (Fig. S3c in the online resource). The sensitivity to the parameters diminishes very rapid with the $\mathrm{CO}_{2}$ price increase. Across the parameters, the corruption coefficient has the highest impact on the MACC at 5-120 USD/tCO ${ }_{2}$, wood price - at 1 and $3 \mathrm{USD} / \mathrm{tCO}_{2}$ (see Table $\mathrm{S} 7$ in the online resource). The agriculture land price reaches its maximum impact on MACC (-5 $\mathrm{MtCO}_{2} /$ year) at $10 \mathrm{USD} / \mathrm{tCO}_{2}$ (Fig. S3a in the online resource), wood price reaches its maximum impact on $\mathrm{MACC}\left(-5 \mathrm{MtCO}_{2} /\right.$ year) at $15 \mathrm{USD} / \mathrm{tCO}_{2}$ (Fig. S3b in the online resource).

At $50 \%$ variation of the parameters, the MACC is most sensitive when the $\mathrm{CO}_{2}$ price is 15 $\mathrm{USD} / \mathrm{tCO}_{2}$ (Fig. $\mathrm{S} 3 \mathrm{a}-\mathrm{c}$ in the online resource). At this $\mathrm{CO}_{2}$ price, a decrease of corruption coefficient causes deviation of MACC by $-51 \mathrm{MtCO}_{2} /$ year (Fig. S3c in the online resource). The corruption coefficient has the highest effect on MACC across the parameters at 3-50 $\mathrm{USD} / \mathrm{tCO}_{2}$, the agriculture land price - at $60-120 \mathrm{USD} / \mathrm{tCO}_{2}$ and the wood price - at $1 \mathrm{USD} /$ $\mathrm{tCO}_{2}$ (see Table $\mathrm{S} 8$ in the online resource). Agriculture land price reaches its maximum impact on MACC (27 $\mathrm{MtCO}_{2} /$ year) at $10 \mathrm{USD} / \mathrm{tCO}_{2}$ (Fig. S3a in the online resource), wood price reaches its maximum impact on $\mathrm{MACC}\left(22 \mathrm{MtCO}_{2} /\right.$ year) at $10 \mathrm{USD} / \mathrm{tCO}_{2}$ (Fig. S3b in the online resource).

At $90 \%$ variation of the parameters, the MACC is most sensitive at $25 \mathrm{USD} / \mathrm{tCO}_{2}$ (Fig. $\mathrm{S} 3 \mathrm{a}-\mathrm{c}$ in the online resource). At this $\mathrm{CO}_{2}$ price, decrease of the corruption coefficient 
causes deviation of the MACC by $-70 \mathrm{MtCO}_{2}$ /year (Fig. S3c in the online resource). The effect of the corruption coefficient variation diminishes slowly and has the highest impact on MACC across the parameters at 3 and $10-120 \mathrm{USD} / \mathrm{tCO}_{2}$ (see Table S9 in the online resource). An agriculture land price has a lower impact on the MACC, with a maximum of $15 \mathrm{USD} / \mathrm{tCO}_{2}$ (31 $\mathrm{MtCO}_{2}$ /year) (Fig. S3a in the online resource), exceeding the impacts of variations of the corruption coefficient and the wood price at $5 \mathrm{USD} / \mathrm{tCO}_{2}$. The wood price has the highest effect across the parameters at $1 \mathrm{USD} / \mathrm{tCO}_{2}$ and reaches its maximum impact (33 $\mathrm{MtCO}_{2} /$ year) at $10 \mathrm{USD} / \mathrm{tCO}_{2}$ (Fig. S3b in the online resource).

Similar to Brazil, the corruption coefficient has the largest impact on the MACC at all levels of the parameter changes. Increasing the amplitude of the parameter variation, the maximum impact shifts from $10 \mathrm{USD} / \mathrm{tCO}_{2}$ to $25 \mathrm{USD} / \mathrm{tCO}_{2}$. Agriculture land price makes a noticeable effect on the $\mathrm{CO}_{2}$ prices greater than $3 \mathrm{USD} / \mathrm{tCO}_{2}$ at 50 and $90 \%$ parameter variations. An increase of the parameter variation amplitude defuses the $\mathrm{CO}_{2}$ price at which individual parameters cause maximum deviation of MACC (see Tables S7-S9 in the online resource).

\subsection{Global}

At $1-5 \%$ variation of the parameters, deviation of the global MACC follows the shape of respective deviations at $10 \%$ variation of the parameters but the amplitude is smaller. At $10 \%$ variation of the parameters, the global MACC is most sensitive when $\mathrm{CO}_{2}$ price is $5 \mathrm{USD} /$ $\mathrm{tCO}_{2}$ (Fig. 2a-c). At this $\mathrm{CO}_{2}$ price, a decrease of the corruption coefficient makes the highest impact on the MACC - the efficiency of abatement costs decreases by $230 \mathrm{MtCO}_{2} /$ year (Fig. 2c). An increase of the corruption coefficient has a slightly smaller effect on the MACC - the abatement increases by $229 \mathrm{MtCO}_{2} /$ year. The agriculture land price variation influences the MACC considerably - a decrease of the land price yields $172 \mathrm{MtCO}_{2}$ /year higher abatement while increase of the land price decreases the abatement by $122 \mathrm{MtCO}_{2} /$ year (Fig. 2a). Global MACC's deviation from a baseline (all parameters $c r, w, l$ unchanged) diminishes with the increasing $\mathrm{CO}_{2}$ price slower than the countries' MACCs considered in the study. The variation of corruption coefficient makes the maximum impact on the global MACC across the three parameters at $\mathrm{CO}_{2}$ prices 1-30 and $80 \mathrm{USD} / \mathrm{tCO}_{2}$ (see Table $\mathrm{S} 10$ in in the online resource). The variation of wood price makes the maximum impact on MACC across the three parameters at 40-60 and 100-120 $\mathrm{USD} / \mathrm{tCO}_{2}$. The wood price reaches its maximum impact on $\mathrm{MACC}$ at $15 \mathrm{USD} / \mathrm{tCO}_{2}$ (Fig. 2b).

At $50 \%$ variation of the parameters, the global MACC is most sensitive when $\mathrm{CO}_{2}$ price is $5 \mathrm{USD} / \mathrm{tCO}_{2}$ (Fig. 2a-c). At this $\mathrm{CO}_{2}$ price, a decrease of the corruption coefficient causes deviation of the MACC by $-1310 \mathrm{MtCO}_{2} /$ year (Fig. 2c). The effect of the corruption coefficient variation diminishes by 15 times to $-75 \mathrm{MtCO}_{2} /$ year at $120 \mathrm{USD} / \mathrm{tCO}_{2}$. The corruption coefficient has the largest impact on MACC across the parameters at 1 and 5-30 $\mathrm{USD} / \mathrm{tCO}_{2}$ (see Table S11 in the online resource). The wood price has a considerable effect on $\mathrm{MACC}$ at all $\mathrm{CO}_{2}$ prices with maximal value of $531 \mathrm{MtCO}_{2} /$ year at $5 \mathrm{USD} / \mathrm{tCO}_{2}$ (Fig. 2b) and has the largest effect across the parameters at 40-120 USD/ $\mathrm{tCO}_{2}$. The agriculture land price has the maximum impact on MACC (903 $\mathrm{MtCO}_{2} /$ year) at $3 \mathrm{USD} / \mathrm{tCO}_{2}$ (Fig. 2a) when it overcomes the effect of the other parameters.

At $90 \%$ variation of the parameters, the MACC is most sensitive at $20 \mathrm{USD} / \mathrm{tCO}_{2}$ (Fig. 2a-c). At this $\mathrm{CO}_{2}$ price, decrease of the corruption coefficient causes deviation of the MACC by $-3477 \mathrm{MtCO}_{2} /$ year (Fig. 2a). The effect of the corruption coefficient variation diminishes slowly and has the highest impact on MACC across the parameters at 5-120 USD/ 

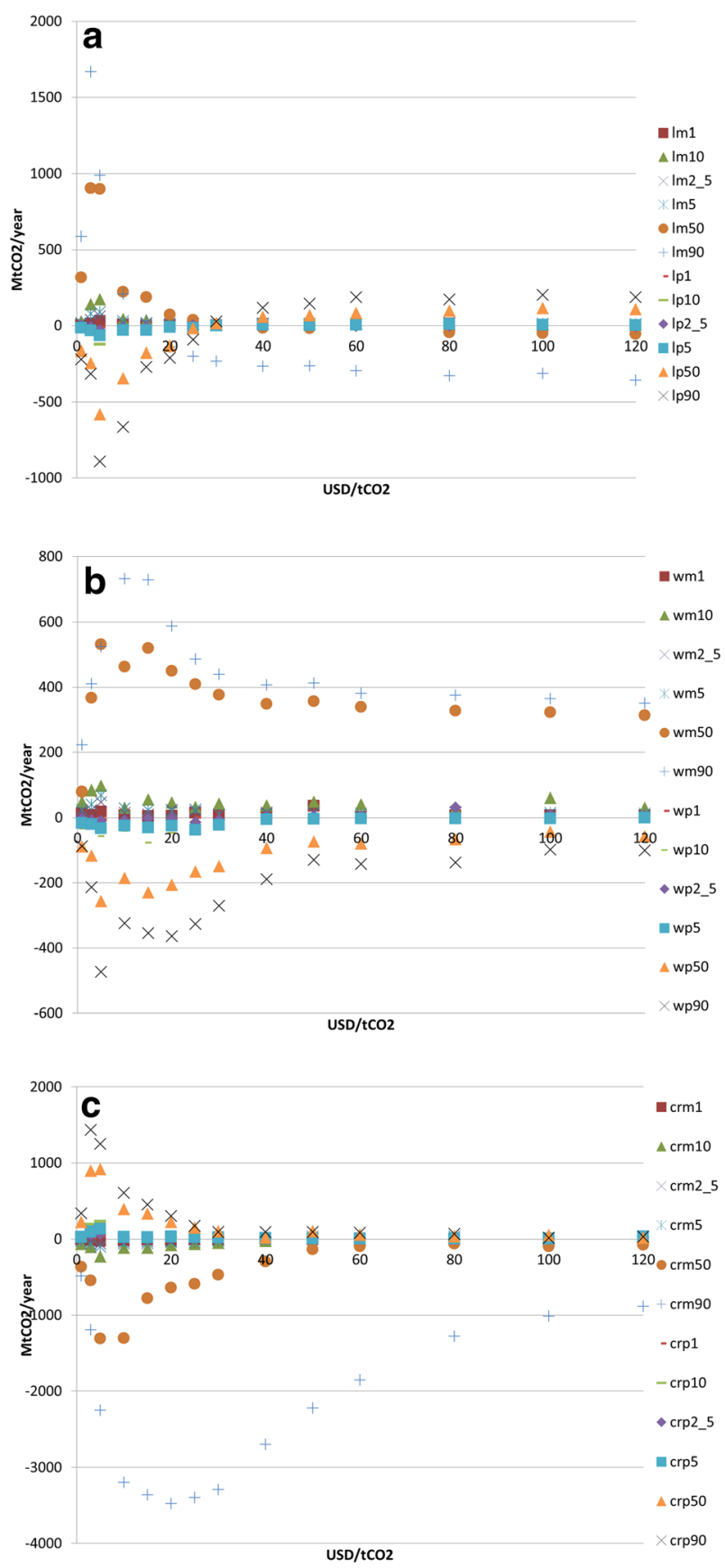

Fig. 2 Sensitivity of marginal abatement cost curve for total biomass $\mathrm{CO}_{2}$ emissions to deviations of agriculture land price (a), wood price (b), and corruption coefficient (c) globally in 2030

$\mathrm{tCO}_{2}$ (see Table $\mathrm{S} 12$ in the online resource). The agriculture land price has a lower impact with the maximum of $5 \mathrm{USD} / \mathrm{tCO}_{2}$ (1699 $\mathrm{MtCO}_{2}$ /year) (Fig. 2a), exceeding the impact of the other 
parameters at 1 and $3 \mathrm{USD} / \mathrm{tCO}_{2}$. The wood price reaches its maximum impact on MACC (733 $\mathrm{MtCO}_{2}$ /year) at $10 \mathrm{USD} / \mathrm{tCO}_{2}$ (Fig. 2b).

The corruption coefficient has the largest impact on the MACC at all levels of the parameter changes. Increasing the amplitude of the parameter variation, the maximum impact shifts from $5 \mathrm{USD} / \mathrm{tCO}_{2}$ (at 10 and $50 \%$ variation) to $20 \mathrm{USD} / \mathrm{tCO}_{2}$ (at $90 \%$ variation). The wood price has relatively even impact at all $\mathrm{CO}_{2}$ prices, while agriculture land price has two picks - higher at low $\mathrm{CO}_{2}$ prices and lower at high $\mathrm{CO}_{2}$ prices. Increase of the parameter variation amplitude to $90 \%$ defuses the $\mathrm{CO}_{2}$ price at which individual parameters cause maximum deviation of MACC (see Tables S10-S12 in the online resource). MACCs for 0-90\% deviations of the agriculture land price, wood price, and the corruption coefficient are presented in Fig. 3a-c.

\section{Discussion}

The parameter deviation was applied to all $\mathrm{CO}_{2}$ price runs, thus serving a bias for MACC. In this case, the MACC deviation is caused by the model non-linearity across $\mathrm{CO}_{2}$ prices, i.e., different sensitivity of the emissions to the same deviation of a parameter at zero and non-zero $\mathrm{CO}_{2}$ prices. For the studied countries and globally, the emission response to the alteration of agriculture land price is very high at $\mathrm{CO}_{2}$ prices 3-10 USD/ $/ \mathrm{CO}_{2}$ symmetrically to negative and positive deviations of the parameter (see Fig. 4 for the global case).

The emission response to wood price alteration has different shapes in the studied countries, while the global case incorporates features of all countries (Fig. 5). In Brazil, the sensitivity is high at all $\mathrm{CO}_{2}$ prices but at the prices $1-5 \mathrm{USD} / \mathrm{tCO}_{2}$, the sensitivity changes its sign (with a maximum at $10 \mathrm{USD} / \mathrm{tCO}_{2}$ ). The "anomaly" is explained by the fact that at some $\mathrm{CO}_{2}$ prices an increase of wood price causes an increase of deforestation rate. This is because a part of the deforested wood is sold that pushes a switching from forestry to agriculture. This is the effect of the interaction between agricultural land price, $\mathrm{CO}_{2}$ price, and wood price. The effect comes from the decision-making algorithm of G4M: conversion from forest to agriculture is based on the highest level of net present value (NPV) that can be achieved by one of these land use alternatives. In this case, a higher wood price is not enough for economically sustainable forestry and (as a one-time profit from selling the wood) adds an incentive for moving to agriculture (deforestation) (Gusti and Kindermann 2011). In Indonesia, the emission response to wood price is variable over the $\mathrm{CO}_{2}$ prices with maximum deviations around 3 and $60 \mathrm{USD} /$ $\mathrm{tCO}_{2}$. In Mexico, the emission response to wood price is symmetrical by the sign of the parameter variation with a maximum of 10-15 $\mathrm{USD} / \mathrm{tCO}_{2}$. For Mexico, the same effect of increasing deforestation with increasing wood price at $5-10 \mathrm{USD} / \mathrm{tCO}_{2}$ is observed. The global picture communicates a similar message (Fig. 5): for the carbon price of approximately 10 $\mathrm{USD} / \mathrm{tCO}_{2}$, an increase of wood price increases deforestation, compared to a baseline corresponding to that carbon price $\left(10 \mathrm{USD} / \mathrm{tCO}_{2}\right)$.

The emission response to a variation of the corruption coefficient has a similar shape - with a sharp maximum deflection of the emissions at $\mathrm{CO}_{2}$ prices 3-10 $\mathrm{USD} / \mathrm{tCO}_{2}$ when the corruption coefficient increases (see Fig. 6 for the global case). When the corruption coefficient decreases, the sensitivity is high at a wide range of $\mathrm{CO}_{2}$ prices, reaching its maximum if the corruption coefficient decreases by $90 \%$.

The G4M model is non-linear on, and sensitive to, the variation of the $c r, w$, and $l$ model parameters. The existence of a range of $\mathrm{CO}_{2}$ prices under which the MACCs are very much sensitive to the variation of model parameters is, probably, model-specific and connected to the 

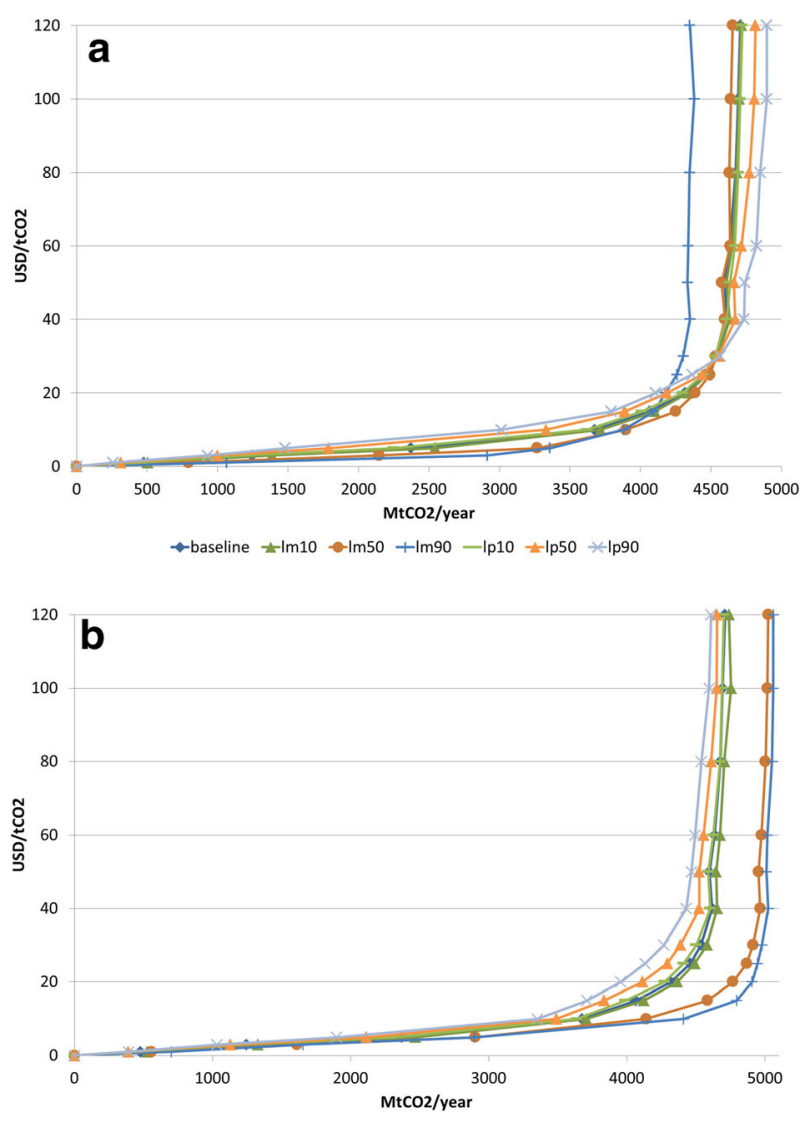

$\rightarrow$ baseline $₫$ wm10 -wm50 +wm90 -wp10 $\pitchfork$ wp50 $*$ wp90

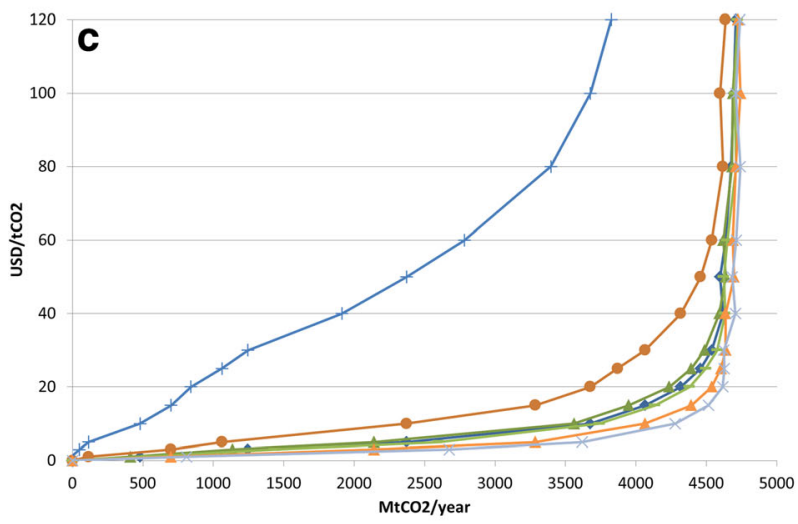

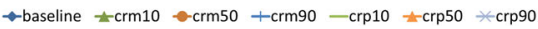

Fig. 3 Marginal abatement cost curves for 0-90\% deviations of agriculture land price (a), wood price (b), and the corruption coefficient $(\mathbf{c})$

simulation of decision making and values of NPVs of the alternative land uses. However, it seems logical that the mitigation potential is less sensitive at $\mathrm{CO}_{2}$ prices corresponding to 


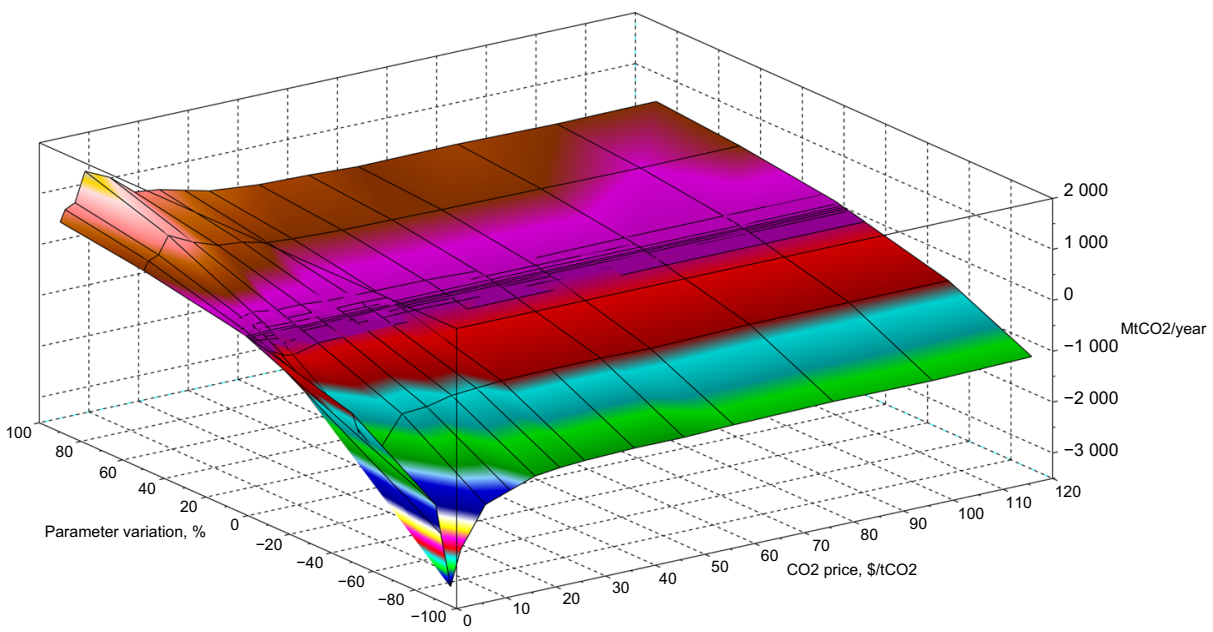

Fig. 4 Sensitivity of total biomass $\mathrm{CO}_{2}$ emissions to agriculture land price globally in 2030

(close-to) the vertical part of the MACC (where an increment of $\mathrm{CO}_{2}$ price results in very little or no change of the mitigation). This is especially relevant to the corruption coefficient that directly impacts the mitigation costs.

Globally, the mitigation amount and the costs modeled by G4M falls within the estimates, provided by the other studies (for example, see Table 1 and an overview by Coren et al. (2011) for more data). Compared to the MACCs for avoided deforestation constructed using three models, the Dynamic Integrated Model of Forestry and Alternative Land Use (DIMA; it is based on spatially explicit deforestation simulation mechanism similar to G4M; however, it was calibrated only globally to net deforestation data from the FAO Forest Resource Assessment as of 2005), a global dynamic partial equilibrium model GCOMAP (acronym for Generalized Comprehensive Mitigation Assessment Process; it simulates afforestation and deforestation in 10 world regions), and the Global Timber Model (GTM; a dynamic optimization model that optimizing forest area, forest age class distribution, and forest management in 250 timber types globally) (Kindermann et al. 2008), it is found that G4M estimates a little

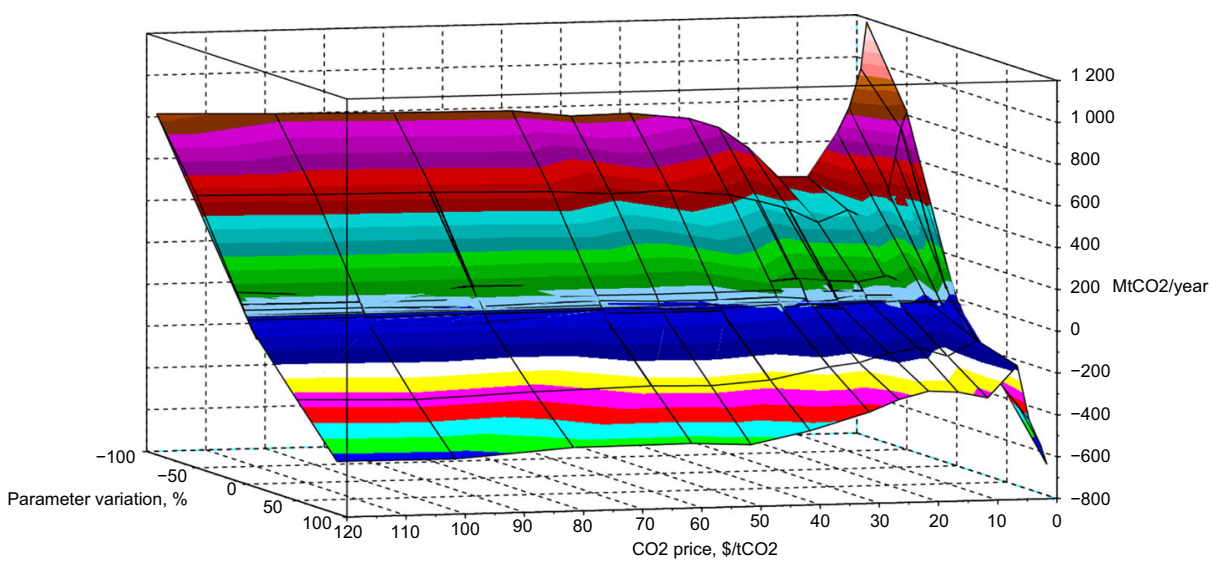

Fig. 5 Sensitivity of total biomass $\mathrm{CO}_{2}$ emissions to wood price globally in 2030 


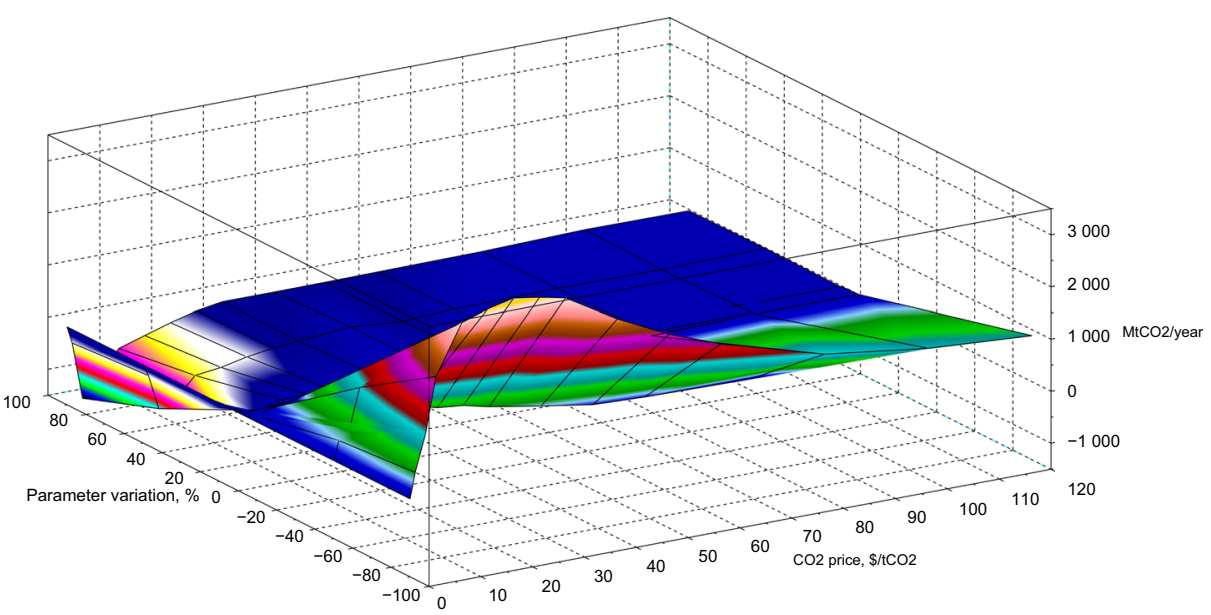

Fig. 6 Sensitivity of total biomass $\mathrm{CO}_{2}$ emissions to corruption coefficient globally in 2030 (greater coefficient means higher efficiency and less corruption)

bit higher mitigation than GTM (the most optimistic of the three models) at $\mathrm{CO}_{2}$ prices below $20 \mathrm{USD} / \mathrm{tCO}_{2}$. One of the reasons of the higher mitigation estimates by $\mathrm{G} 4 \mathrm{M}$ is $5 \% /$ year rising $\mathrm{CO}_{2}$ price comparing to the constant $\mathrm{CO}_{2}$ price in the other studies.

The difference between the smallest and the largest estimates by the three models varies from 1.5 to $2.3 \mathrm{GtCO}_{2}$ /year with a maximum at 20 and $25 \mathrm{USD} / \mathrm{tCO}_{2}$ (Diff 1 in Table 1). If the G4M results are included, the difference increases only at 5,10 , and $15 \mathrm{USD} / \mathrm{tCO}_{2}$ with a maximum of $2.4 \mathrm{GtCO}_{2}$ year, at $15 \mathrm{USD} / \mathrm{tCO}_{2}$ (Diff 2 in Table 1). The absolute values of the MACC deviation are due to the $10 \%$ variation of G4M input parameters, which are one order of magnitude lower at $5 \mathrm{USD} / \mathrm{tCO}_{2}$ and two orders of magnitude lower at higher $\mathrm{CO}_{2}$ prices than the differences due to the application of the different models. The absolute values of the MACC deviation due to the $50 \%$ variation of the G4M input parameters are of the same order of magnitude as the inter-model differences at $\mathrm{CO}_{2}$ prices below $15 \mathrm{USD} / \mathrm{tCO}$. In the case of $90 \%$ variation of the parameters, the MACC deviations are greater than the inter-model

Table 1 Mitigation costs, respective mitigation of $\mathrm{CO}_{2}$ emissions in 2030 , $\mathrm{GtCO}_{2}$ /year, from avoided deforestation estimated by DIMA, GCOMAP, GTM (derived from Fig. 3 in Kindermann et al. 2008, p.10305), and G4M models (current study); difference of the $\mathrm{CO}_{2}$ emission mitigation estimates of the first three models without G4M (Diff 1), $\mathrm{GtCO}_{2}$ /year, and including G4M (Diff 2); maximal deviation of $\mathrm{MACC} \mathrm{GtCO}_{2} /$ year, at $10 \%$ variation (G4M10), 50\% variation (G4M50), and 90\% variation (G4M90) of G4M input parameters

\begin{tabular}{llllllllll}
\hline $\begin{array}{l}\mathrm{CO}_{2} \text { price, } \\
\text { USD/tCO }\end{array}$ & DIMA & GCOMAP & GTM & G4M & Diff 1 & Diff 2 & G4M10 & G4M50 & G4M90 \\
\hline 5 & 0.2 & 0.8 & 1.7 & 1.8 & 1.5 & 1.6 & 0.19 & 1.1 & 1.8 \\
10 & 0.6 & 1.9 & 2.5 & 2.9 & 1.9 & 2.3 & 0.08 & 1.1 & 2.5 \\
15 & 0.8 & 2.1 & 3 & 3.2 & 2.2 & 2.4 & 0.1 & 0.6 & 2.7 \\
20 & 1.1 & 2.3 & 3.4 & 3.4 & 2.3 & 2.3 & 0.06 & 0.5 & 2.8 \\
25 & 1.2 & 2.5 & 3.5 & 3.5 & 2.3 & 2.3 & 0.04 & 0.4 & 2.7 \\
30 & 1.5 & 2.8 & 3.6 & 3.6 & 2.1 & 2.1 & 0.04 & 0.3 & 2.6 \\
40 & 1.7 & 3.2 & 3.7 & 3.6 & 2 & 2 & 0.04 & 0.3 & 2.1 \\
50 & 2 & 3.3 & 3.8 & 3.6 & 1.8 & 1.8 & 0.03 & 0.3 & 1.8 \\
70 & 2.1 & 3.4 & 3.8 & 3.7 & 1.7 & 1.7 & 0.03 & 0.3 & 1.5 \\
100 & 2.1 & 3.4 & 3.8 & 3.7 & 1.7 & 1.7 & 0.03 & 0.3 & 0.8 \\
\hline
\end{tabular}


differences at $\mathrm{CO}_{2}$ prices below $50 \mathrm{USD} / \mathrm{tCO}_{2}$. From the comparison, it can be concluded that the quality of input data may be as important as the application of a few different models for construction of the MACCs. This conclusion is true at least in the case of G4M, as well as for the modeling study of the GHG mitigation potential in agriculture and forestry sectors in the USA by Schneider and McCarl (2006) who report a variation of the economic mitigation potential from -55 to $85 \%$ depending on the modeling assumptions.

In general, the results found in this study are in line with Kesicki (2013), who made a sensitivity analysis of MACCs for UK transport sector to fossil fuel prices and van Vuuren et al. (2009), who compared the results of 6 IAMs, statistical analysis combining results of different model studies, and two bottom-up assessments, that estimates of economic mitigation potentials are more robust at higher $\mathrm{CO}_{2}$ prices. However, in the study by Schneider and McCarl (2006), the bias of the mitigation potential is greater at higher $\mathrm{CO}_{2}$ prices because mitigation activities shift to afforestation and energy crop plantations which compete for agriculture land and distort the market of agriculture commodities. The reason for the contrasting results by Schneider and McCarl (2006) may be because Schneider and McCarl (2006) considered GHG mitigation policies in a single country where considered in the study mitigation measures in forestry are more expensive than in agriculture.

The results of the MACCs sensitivity to variation of the G4M model parameters and the model inter-comparison analysis suggest some implications for the design of REDD mitigation policies. In particular, medium-term mitigation policies, which usually apply low $\mathrm{CO}_{2}$ prices, may be more vulnerable to the uncertainty of information on corruption and the quality of governance in target countries. This may occur because the estimates of economic mitigation potential are more sensitive to the financial efficiency at low $\mathrm{CO}_{2}$ prices. The uncertainty of input data and model assumptions has less impact on the MACCs at high $\mathrm{CO}_{2}$ prices that are usually employed in designing long-term mitigation policies. Therefore, we would advise policymakers to develop policies taking into account quality of institutions in target countries. However, more research, along with the application of other models, is needed to improve the validity of these findings, as they are currently based on a sensitivity study exploiting a single model (G4M) and key socioeconomic parameters in this model and supported by the analysis of a few available published studies.

\section{Conclusions}

Because of the G4M model non-linearity, the MACCs are sensitive to the variation of the model parameters, irrespective of the fact that the same parameter variations are applied in both zero- $\mathrm{CO}_{2}$ price and non-zero- $\mathrm{CO}_{2}$ price runs. Since the integrated assessment models in general are complex computer models with non-linearity, one may expect all MACCs constructed using such models are sensitive to the variation of the model parameters.

The MACCs constructed using G4M are much more sensitive to parameter variation at a certain range of $\mathrm{CO}_{2}$ prices, usually low $\mathrm{CO}_{2}$ prices. The MACCs for total biomass $\mathrm{CO}_{2}$ emissions constructed using G4M are most sensitive to the variation of corruption coefficient (a combination of "political stability," "government effectiveness," and "control of corruption" indexes; measuring the efficiency of use of abatement costs) and, secondly, to agriculture land price. The uncertainties resulting from modeling assumptions are as important as the quality of input data. This study and most of the considered published results indicate that with the high $\mathrm{CO}_{2}$ price, MACCs are more robust. 
Based on the results of this study, it is suggested that it is vital to consider MACCs compatible with the institutions in place when designing medium-term mitigation policies with generally low $\mathrm{CO}_{2}$ prices. When designing long-term mitigation policy characterized by high $\mathrm{CO}_{2}$ prices, the sensitivity of the MACCs to the considered drivers is of secondary importance. These statements must be taken with caution as they are based on the sensitivity study of one model (G4M) and key socioeconomic parameters in this model and a limited number of publications containing data from which the respective information was extracted.

Acknowledgements Open access funding provided by International Institute for Applied System Analysis (IIASA). The work has been carried out within the project "Options Market and Risk-Reduction Tools for REDD+" funded by the Norwegian Agency for Development Cooperation under agreement number QZA-0464 QZA-13/0074 and partly supported by the project "Delivering Incentives to End Deforestation: Global Ambition, Private/ Public Finance and Zero-Deforestation Supply Chains" funded by the Norwegian Agency for Development Cooperation under agreement number QZA- 0464, QZA-16/0218.

Open Access This article is distributed under the terms of the Creative Commons Attribution 4.0 International License (http://creativecommons.org/licenses/by/4.0/), which permits unrestricted use, distribution, and reproduction in any medium, provided you give appropriate credit to the original author(s) and the source, provide a link to the Creative Commons license, and indicate if changes were made.

\section{References}

Angelsen A, Gierløff CW, Beltrán AM, den Elzen M (2014) REDD credits in a global carbon market: options and impacts. Nordic Council of Ministers. Nordisk Ministerråd, Copenhagen $102 \mathrm{p}$

Anger N, Sathaye J (2008) Reducing Deforestation and Trading Emissions: Economic Implicationsfor the postKyoto Carbon Market. ZEW - Centre for European Economic Research Discussion Paper No. 08016. Available at SSRN: https://doi.org/10.2139/ssrn.1114044

Benitez PC, Obersteiner M (2006) Site identification for carbon sequestration in Latin America: a grid-based economic approach. Forest Policy Econ 8:636-651

Bosello F, Parrado R, Rosa R, Eboli F (2015) REDD in the Carbon Market: A General Equilibrium Analysis. Environ Model Assess 20:103-115. https://doi.org/10.1007/s10666-014-9419-1

Bosetti V, Lubowski R, Golub A, Markandya A (2011) Linking reduced deforestation and a global carbon market: implications for clean energy technology and policy flexibility. Environ Dev Econ 16(4):479-505

Böttcher H, Verkerk PJ, Gusti M, Havlik P, Grassi G (2012) Projection of the future EU forest $\mathrm{CO}_{2}$ sink as affected by recent bioenergy policies using two advanced forest management models. GCB Bioenergy 4 : 773-783

Capros P, De Vita A, Hoeglund-Isaksson L, Winiwarter W, Purohit P, Böttcher H, Frank S, Havlik P, Gusti M, Witzke HP et al. (2013) EU Energy, Transport and GHG Emissions Trends to 2050 - Reference Scenario 2013. European Commission, Publications Office of the European Union, Luxembourg

Capros P, De Vita A, Tasios N, Siskos P, Kannavou M, Petropoulos A, Evangelopoulou S, Zampara M, Papadopoulos D, Nakos Ch, Paroussos L, Fragiadakis K, Tsani S, Karkatsoulis P, Fragkos P, Kouvaritakis N, Hoeglund-Isaksson L, Winiwarter W, Purohit P, Gomez Sanabria A, Frank S, Forsell N, Gusti M, Havlik P, Obersteiner M, Witzke HP, Kesting M (2016) EU Reference Scenario 2016 - Energy, transport and GHG emissions Trends to 2050. UROPEAN COMMISSION Directorate - General for Energy, Directorate General for Climate Action and Directorate - General for Mobility and Transport

Carraro C, Massetti E (2012) Beyond Copenhagen: a realistic climate policy in a fragmented world. Clim Chang 110:523-542

Coren M, Streck C, Myers Madeira E (2011) Estimated supply of RED credits 2011-2035. Clim Pol 11(6):12721288. https://doi.org/10.1080/14693062.2011.579318

Dellink R, Chateau J, Lanzi E, Magné B (2017) Long-term economic growth projections in the shared socioeconomic pathways. Glob Environ Chang 42:200-214 https://doi.org/10.1016/j. gloenvcha.2015.06.004

den Elzen MGJ, Mendoza Beltran A, Piris-Cabezas P, van Vuuren DP (2009) Analysing the international carbon market and abatement costs by 2020 for low concentration targets: policy choices and uncertainties. 
Netherlands Environmental Assessment Agency (PBL), report 500102031, Bilthoven, the Netherlands, http://www.pbl.nl/en/publications/2009/Balancing-the-carbon-market-Analysing-the-international-carbonmarket-and-abatement-costs

Deveny, Nackoney J, Purvis N, Gusti M, Kopp RJ, Myers ME, Stevenson AR, Kindermann G, Macauley MK, Obersteiner M (2009) Forest carbon index: the geography of forests in climate solutions. Joint report by Resources for the Future and Climate Advisers. http://www.rff.org/research/publications/forest-carbonindex-geography-forests-climate-solutions

Ekins P, Kesicki F, Smith AZP (2011) Marginal Abatement Cost Curves: a call for caution. A report from the UCL Energy Institute to, and commissioned by, Greenpeace UK, April 2011

Eliasch J (2008) Climate change: financing global forests : the Eliasch review. Earthscan, London

Eory V, Topp CFE, Moran D, Butler A (2014) Assessing uncertainty in the cost-effectiveness of agricultural greenhouse gas mitigation. Agricultural Economics Society, 88th Annual Conference, April 9-11, 2014, AgroParisTech, Paris, France

Eory V, Topp CF, Butler A, Moran D (2018) Addressing uncertainty in efficient mitigation of agricultural greenhouse gas emissions. J Agric Econ. https://doi.org/10.1111/1477-9552.12269

EPA (2013) Global Mitigation of Non- $\mathrm{CO}_{2}$ Greenhouse Gases: 2010-2030. EPA-430-R-13-011. United States Environmental Protection Agency, Office of Atmospheric Programs (6207J), Washington, DC 20005, 410p. https://www3.epa.gov/climatechange/Downloads/EPAactivities/MAC_Report_2013.pdf

Fan Y, Peng B-B, Xu J-H (2017) The effect of technology adoption on $\mathrm{CO}_{2}$ abatement costs under uncertainty in China's passenger car sector. J Clean Prod 154:578-592

FAO (2010) Global forest resources assessment 2010. http://www.fao.org/forestry/fra/fra2010/en/

Forsell N, Korosuo A, Lauri P, Gusti M, Havlik P, Böttcher H, Hennenberg K (2016) Follow-up study on impacts on resource efficiency of future EU demand for bioenergy (ReceBio follow-up). Publications Office of the European Union, Luxembourg. ISBN 978-92-79-64433-7, 68pp

Frank S, Böttcher H, Gusti M, Havlík P, Klaassen G, Kindermann G, Obersteiner M (2016) Dynamics of the land use, land use change, and forestry sink in the European Union: the impacts of energy and climate targets for 2030. Clim Chang 138:253-266

Fricko et al (2017) The marker quantification of the shared socioeconomic pathway 2: a middle-of-the-road scenario for the $21 \mathrm{st}$ century. Glob Environ Chang 42:251-267. https://oi.org/10.1016/j. gloenvcha.2016.06.004

Gusti M (2010) An algorithm for simulation of Forest management decisions in the global Forest model. Artif Intell N4:45-49

Gusti M, Kindermann G (2011) An approach to modeling landuse change and forest management on a global scale. In SIMULTECH-2011. Proc. of 1st intern. Conf. On simulation and modeling methodologies, technologies and applications, Noordwijkerhout, pp. 180-185

Gusti M, Havlik P, Oberstenier M (2008) Technical description of the IIASA model cluster. International Institute for Applied System Analysis (IIASA). (http://digital.library.unt.edu/ark:/67531/metadc13707/m2/1/high res_d/Gusti_IIASA_model_cluster.pdf)

Havlík P, Valin $\bar{H}$, Gusti M, Schmid E, Forsell N, Herrero M, Khabarov N, Mosnier A, Cantele M, Obersteiner M (2015) Climate change impacts and mitigation in the developing world : an integrated assessment of the agriculture and forestry sectors. Policy Research working paper; no. WPS 7477. Washington, D.C.: World Bank Group. http://documents.worldbank.org/curated/en/2015/11/25250682/climate-change-impactsmitigation-developing-world-integrated-assessment-agriculture-forestry-sectors

Houghton RA, Byers B, Nassikas AA (2015) A role for tropical forests in stabilizing atmospheric $\mathrm{CO}_{2}$. Nat Clim Chang 5:1022-1023. https://doi.org/10.1038/nclimate2869

Kaufmann D, Kraay A, Mastruzzi M (2005) Governance Matters IV: Governance Indicators for 1996-2004, World Bank Policy Research Working Paper Series No. 3630. World Bank, http://ssrn.com/abstract=718081

Kesicki F (2011) Marginal abatement cost curves for policy-making - expert-based vs model-derived curves. UCL Energy Institute, University College London. www.homepages.ucl.ac.uk/ ucft347/Kesicki_MACC. pdf. Accessed 14 September 2015

Kesicki F (2013) Marginal abatement cost curves: combining energy system modelling and decomposition analysis. Environ Model Assess 18:27-37. https://doi.org/10.1007/s10666-012-9330-6

Kesicki F, Strachan N (2011) Marginal abatement cost (MAC) curves: confronting theory and practice. Environ Sci Pol 14:1195-1204

Kindermann G, Obersteiner M, Rametsteiner E, McCallcum I (2006) Predicting the deforestation-trend under different carbon-prices. Carbon Balance and Manag 1:15. https://doi.org/10.1186/1750-0680-1-15

Kindermann G., Obersteiner M., Sohngen B., Sathaye J., Andrasko K., Rametsteiner E., Schlamadinger B., Wunder S. and Beach R. (2008) Global cost estimates of reducing carbon emissions through avoided deforestation. PNAS, vol. 105, N 30, pp. 10302-10307 
Klepper G, Peterson S (2003) On the robustness of marginal abatement cost curves: the influence of world energy prices. Kiel Working Paper No. 1138. Kiel Institute for World Economics, Kiel, Germany, 29p

McKinsey\&Company (2013) Pathways to a low-carbon economy: Version 2 of the global greenhouse gas abatement cost curve. http://www.mckinsey.com/business-functions/sustainability-and-resourceproductivity/our-insights/pathways-to-a-low-carbon-economy

Michaelova A, Jotzo F (2003) Impacts of transaction costs and institutional rigidities on the share of the Clean Development Mechanism in the global greenhouse gas market. Paper für die Sitzung des Ausschusses Umweltökonomie im Verein für Socialpolitik, Rostock 1.-3.5. 2003

Overmars K, Stehfest E, Tabeau A, van Meijl H, Beltrán AM, Kram T (2014) Estimating the opportunity costs of reducing carbon dioxide emissions via avoided deforestation, using integrated assessment modelling. Land Use Policy 41:45-60

Pałka P, Stańczak J, Radziszewska W, Nahorski Z (2018) Experimental validation of uncertain GHG emission permit markets via multi-agent SIMULATION

Pickl S. (2018) Uncertainty in trading emissions: an agent based and system dynamics approach based on the TEM model

Radov D., Klevnas P., Lindovska, Hanif A et al. (2012) The demand for greenhouse gas emissions reduction investments: an Investors' marginal abatement cost curve for Ukraine. Prepared for EBRD. NERA economic consulting. http://www.ebrd.com/downloads/research/economics/publications/specials/Ukraine_MACC_ report_ENG.pdf

Riahi K, Rao S, Krey V, Cho C, Chirkov V, Fischer G, Kindermann G, Nakicenovic N, Rafaj P (2011) RCP 8.5-a scenario of comparatively high greenhouse gas emissions. Clim Chang 109:33-57

Schneider UA, McCarl BA (2006) Appraising agricultural greenhouse gas mitigation potentials: effects of alternative assumptions. Agric Econ 35:277-287. https://doi.org/10.1111/j.1574-0862.2006.00162.x

Sheng J, Han X, Zhou H, Miao Z (2016) Effects of corruption on performance: evidence from the UN-REDD Programme. Land Use Policy 59:344-350

Suyanto S, Ekadinata A, Sofiyuddin M, Rahmanullah A (2014) Opportunity costs of emissions caused by landuse changes. Open J For 4:85-90. https://doi.org/10.4236/ojf.2014.41013

UN-REDD (2016) Towards a common understanding of REDD+ under the UNFCCC. A UN-REDD Programme document to foster a common approach of REDD+ implementation. Technical Resource Series. UN-REDD Programme Secretariat, International Environment House, 11-13 Chemin des Anémones, CH-1219 Châtelaine, Geneva, Switzerland

Valatin G. (2012) Marginal abatement cost curves for UK forestry. Forestry Commission Research Report. Forestry Commission, Edinburgh. 20p

van Vuuren D, Hoogwijk M, Barker T, Riahi K, Boeters S, Chateau J, Scrieciu S, van Vliet J, Masui T, Blok K, Blomen E, Kram T (2009) Comparison of top-down and bottom-up estimates of sectoral and regional greenhouse gas emission reduction potentials. Energy Policy 37(12):5125-5139. https://doi.org/10.1016/j. enpol.2009.07.024

Vogt-Schilb A, Hallegatte S, De Gouvello C (2015) Marginal abatement cost curves and quality of emission reductions: a case study on Brazil. Clim Pol 15(6):703-723

Wagner F, Amann M, Borken-Kleefeld J, Cofala J, Höglund-Isaksson L, Purohit P, Rafaj P, Schöpp W, Winiwarter W (2012) Sectoral marginal abatement cost curves: implications for mitigation pledges and air pollution co-benefits for annex I countries. Sustain Sci 7:169-184. https://doi.org/10.1007/s11625-0120167-3

Webster M, Sue Wing I, Jakobovits L (2010) Second-best instruments for near-term climate policy: intensity targets vs. the safety valve. J Environ Econ Manag 59(3):250-259 